1. MBBS, FCPS

Assistant Professor Medicine

Shalamar Institute of Health

Sciences Lahore.

2. MBBS, FCPS

Associate Professor Medicine

SIHS Lahore.

3. MBBS, FCPS

(Gastroenterology)

Senior Registrar, SIHS Lahore

4. MBBS, FCPS, MRCP, FRCP

Professor of Medicine

POF Hospital Wah cantt

Correspondence Address:

Dr. Sarwat lqbal

1. MBBS, FCPS

Assistant Professor Medicine

Shalamar Institute of Health Sciences,

Lahore.

saiqef@gmail.com

Article received on: 09/07/2015

Accepted for publication:

17/08/2015

Received after proof reading:

$13 / 11 / 2015$

\section{DECOMPENSATED CIRRHOSIS; PREVALENCE OF GASTRIC VARICES}

Dr. Sarwat Iqbal', Dr. Muhammad Haroon Yousaf ${ }^{2}$, Dr. Muhammad Ifitikhar Yousuf ${ }^{3}$, Dr. Wasim-Uddin ${ }^{4}$

ABSTRACT...: Cirrhosis with subsequent portal hypertension is a major health problem worldwide. Among various etiologies, HCV is the leading cause of chronic hepatocellular injury. Cirrhosis being the commonest cause of portal hypertension results in a spectrum of complications. Approximately $5-15 \%$ of cirrhotic develop varices. Gastric varices although present less frequently as compared to esophageal varices but are associated with greater mortality and morbidity. Objectives: To determine prevalence of Gastric varices in patients with decompensated cirrhosis. Study Design: Cross sectional study. Place \& Duration: Carried out at two centers, Pakistan Ordinance Factories Hospital Wah Cantt and Shalimar Hospital Lahore from Jan 2014 to Jan 2015. Subjects: A total of 421subjects of decompensate cirrhosis were included in the study. Methods: Patients with decompensate cirrhosis of any etiology who were visiting the two hospitals as inpatient or outpatient were included in the study. Upper Gl endoscopy was done in all these subjects for determination of gastric varices. Results: Among 421 patients of decompensate cirrhosis, frequency of gastric varices was $10.9 \%$, GOV1 as the most common variant. Gastric varices contributed to $5.4 \%$ of all variceal bleeds. Conclusion: Gastric varices are found in significant number of patients of decompensate cirrhosis. Since gastric varices are associated with increased mortality and poor outcomes, these should be carefully looked during upper Gl endoscopy. Successful management of gastric variceal hemorrhage necessitates availability of expertise and newer diagnostic modalities.

Key words: $\quad$ Cirrhosis, Portal hypertension, Gastric varices, Variceal hemorrhage.

Article Citation: Iqbal S, Yousaf MH, Yousuf MI, Wasim-Uddin. Decompensated cirrhosis; prevalence of gastric varices. Professional Med J 2015;22(11):1397-1402. DOI: $10.17957 / T P M J / 15.3016$

\section{INTRODUCTION}

Chronic liver disease and its complications are a major health problem worldwide and significant cause of morbidity and mortality among patients. It is the commonest cause of portal hypertension and more than $60 \%$ of patients with cirrhosis eventually develop portal hypertension, which in turn is responsible for the development of as cites and esophagogastric varices. Approximately $5-15 \%$ of patients with cirrhosis per year develop varices. ${ }^{1}$

Varices can be either esophageal or gastric where esophageal ones are much more frequent. Gastric varices are present in $20 \%$ of patients with portal hypertension of all etiologies. ${ }^{2,3}$ Gastric varices occur in $5-33 \%$ of patients with portal hypertension due to underlying cirrhosis ${ }^{4}$, whereas isolated gastric varicesare present in
$5 \%$ of cirrhotics. ${ }^{5}$ They represent $10-15 \%$ of all variceal bleeds. ${ }^{6}$ They may develop either due to generalized or segmental portal hypertension as in splenic vein thrombosis. ${ }^{2}$ Gastric varices are classified based on their location in stomach and relation to esophageal varices, described by Sarin and Kumar. ${ }^{2}$ GOV (gastro-esophageal varices) when they extend from esophagus to stomach and IGV (isolated gastric varices) in the absence of esophageal varices. GOV are subdivided into GOV1, extending along lesser curvature of stomach and GOV2, extending along greater curvature of stomach. In the same way IGV are subdivided into IGV1 (located in gastric fundus) and IGV2 (located in antrum, corpus, pylorus or upper duodenum). ${ }^{2,3,7}$ (figure-1) 


\section{SARIN CLASSIFICATION}

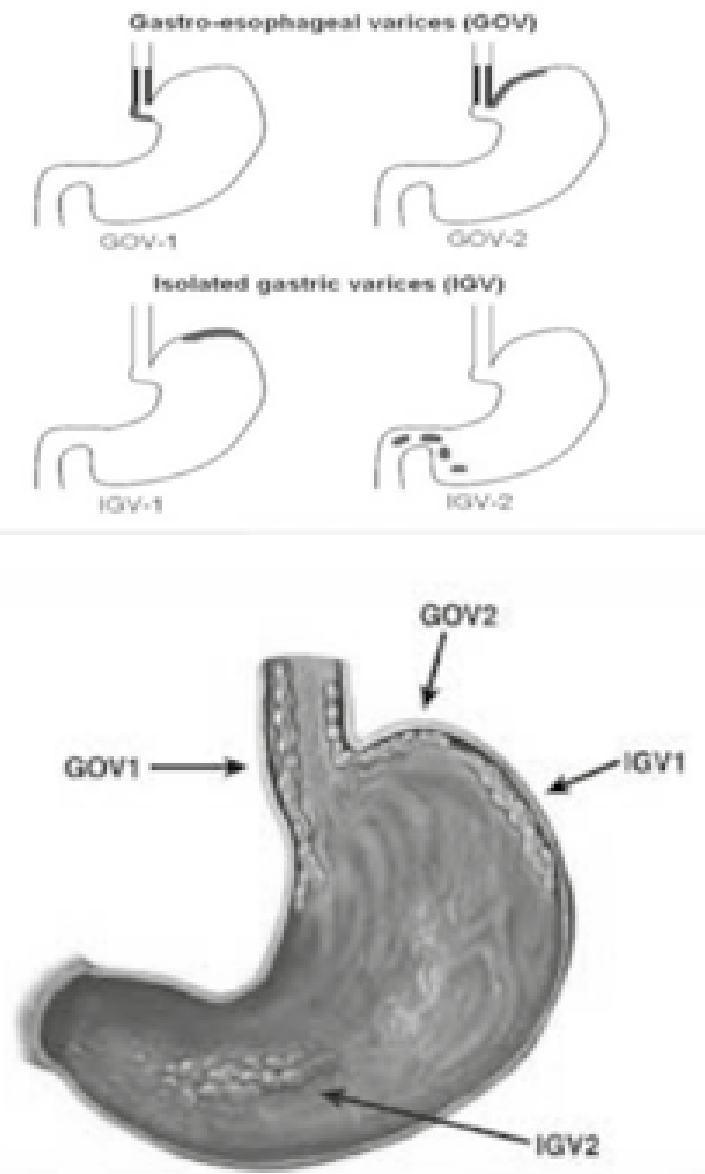

Figure-1. Gastric Varices sub-types; Sarin Classification

Gastric varices although bleed less frequently as compared to esophageal varices but are associated with more severe bleeding and morbidity. ${ }^{2,8}$ Bleeding gastric varices can be technically difficult to treat. They rebleed frequently despite initially successful endoscopic therapy. The reason for this disparity has been explained by our knowledge of portal system which revealed that gastric varices have a large larger vascular bed and multiple communications making conventional therapies less successful.

Multiple studies have now concluded that tissue adhesives like cyanoacrylate are now the standard of treatment in acute gastric variceal bleed wherever expertise are available. Cyanoacrylate has been shown to achieve good homeostasis with fewer complications and decreased frequen- cy of rebleeds as compared to variceal band ligation. As far as prevention of recurrent bleeding is concerned, it can be achieved with use of $\beta$-blockers in a similar fashion as those for esophageal varices. ${ }^{9}$

Complications of cirrhosis are basically the same irrespective of etiology. Etiology of underlying cirrhosis worldwide as well as in Pakistan is predominantly HCV, HBV or co-infection, majority being $\mathrm{HCV}$ related..$^{1,10}$

Since gastric varices are associated with higher morbidity and mortality, these should be carefully looked for during upper Gl endoscopy and their presence documented. A similar study conducted at Agha Khan University Hospital provided good statistical evidence about gastric varices ${ }^{4}$ and this study conducted in another set of population will further strengthen the existing data. Also it will put an emphasis on necessity and availability of newer therapeutic measures

\section{METHODOLOGY}

A total of 421 patients with evidence of decompensate cirrhosis presenting to inpatient, Outpatient and Endoscopy department of the two hospitals were subjected to further evaluation. Inclusion criteria were cirrhotic patients with any one of the following; $h / o$ variceal bleed, encephalopathy, splenomegaly, as cites, thrombocytopenia or portal vein diameter of $\geq 13 \mathrm{~mm}$ on ultrasonography. Patients with other major organ failure and co-existent HCC were excluded from the study.

Thorough clinical examination was done in all patients to look for ascites, splenomegaly and hepatic encephalopathy. Baseline investigations; blood complete count, liver function tests, prothrombin time, serum albumin concentration were carried out. Abdominal ultrasound was done to ascertain presence of portal hypertension in terms of as cites, splenomegaly and portal vein dilatation and to look for any underlying GI malignancy.

Hepatitis B/C serology was done in those previously not evaluated for viral etiology. Patients were categorized into HBV related, HCV related 
and non $\mathrm{B} / \mathrm{C}$ related cirrhosis on the basis of etiology. Patients were also categorized individually into respective Child Class. Upper Gl endoscopy was done to look for gastric varices and their subtype. Co-existent portal gastropathy and esophageal varices were also noted.

All data was entered and analyzed using SPSS version 16.0. For quantitative variable of age mean \pm standard deviation has been presented. For categorical variables like gender, etiology of cirrhosis, Child class, presence of gastric varices, co-existent esophageal varices/portal gastropathy, Sarin class, $\mathrm{H} / \mathrm{O}$ of variceal bleed frequencies (percentages) are presented.

\section{RESULTS}

Four hundred and twenty one patients with decompensated cirrhosis from the two centers were enrolled in the study (218 males and 203 females). Mean age was $54 \pm 11 \mathrm{yrs}$ (table-I). Chronic HCV was the main etiological factor. On further evaluation and screening $76 \%$ patients had esophageal varices and $76.4 \%$ had portal gastropathy. Most of the times both were seen in combination. Gastric varices were found in $10.9 \%$ of patients out of which GOV1, GOV2, IGV1 and IGV2 comprised $54.3 \%, 17.3 \%, 23.9 \%$ and $4.3 \%$ respectively (table-II and III). Of $52 \%$ of total bleeds $5.4 \%$ were attributable to gastric varices. If considered independently $26 \%$ of gastric varices ultimately bled necessitating use of tissue adhesives and $49.8 \%$ of esophageal varices presented with upper $\mathrm{Gl}$ bleed requiring band ligation. Apparently seems smaller percentage but gastric varices were associated with higher percentage of rebleeds and mortality recorded during hospital stay and within 1 week of discharge after initial bleeding episode (table-IV). Another difference that was noted is that gastric varices were found more in males (70\%) as compared to females (30\%).

\begin{tabular}{|c|c|}
\hline Minimum & $18 \mathrm{yrs}$ \\
\hline Maximum & $90 \mathrm{yrs}$ \\
\hline Mean & $54 \mathrm{yrs}$ \\
\hline Std deviation & 11 \\
\hline Table-I. Age Distribution \\
\hline
\end{tabular}

\begin{tabular}{|c|c|}
\hline Characteristics & $\begin{array}{c}\text { Percentage } \\
\text { (n=421) }\end{array}$ \\
\hline Males & $218(51.7 \%)$ \\
\hline Females & $203(48.2 \%)$ \\
\hline Etiology & \\
\hline HCV & $381(90.4 \%)$ \\
\hline HBV & $10(2.3 \%)$ \\
\hline Non B/C & $30(7.1 \%)$ \\
\hline Esophageal varices & $320(76 \%)$ \\
\hline Portal gastropathy & $322(76.4 \%)$ \\
\hline Gastric varices & $46(10.9 \%)$ \\
\hline Bleeding history & $222(52.7 \%)$ \\
\hline Child Class & $101(24 \%)$ \\
\hline A & $219(52 \%)$ \\
\hline B & $10(24 \%)$ \\
\hline C & \\
\hline Table-II. Baseline Characteristics \\
\hline
\end{tabular}

\begin{tabular}{|c|c|}
\hline Gastric Varix subtype & $\begin{array}{c}\text { Percentage } \\
(\mathbf{n = 4 6 )}\end{array}$ \\
\hline GOV1 & $25(54.3 \%)$ \\
\hline GOV2 & $8(17.3 \%)$ \\
\hline IGV1 & $11(23.9 \%)$ \\
\hline IGV2 & $2(4.3 \%)$ \\
\hline Table-III. Subtypes of Gastric Varices \\
\hline
\end{tabular}

\begin{tabular}{|c|c|c|} 
& $\begin{array}{c}\text { Esophageal } \\
\text { Varices } \mathbf{( n = 1 5 9 )}\end{array}$ & $\begin{array}{c}\text { Gastric } \\
\text { Varices } \mathbf{( n = 1 2 )}\end{array}$ \\
\hline Rebleed & $11(7 \%)$ & $5(41 \%)$ \\
Mortality & $2(1.2 \%)$ & $1(8.3 \%)$ \\
\hline \multicolumn{2}{|c|}{ Table-IV. Bleeding Complications }
\end{tabular}

\section{DISCUSSION}

Cirrhosis is the ultimate outcome of chronic hepatocellular injury. It is one of the leading cause of morbidity and mortality worldwide. A number of etiologies have been implicated, the commonest being chronic viral hepatitis where chronic HCV takes the lead. Contrary to that chronic ethanol ingestion is sharing a larger percentage in western world. This study showed frequency of HCV and $\mathrm{HBV}$ as $90.4 \%$ and $2.3 \%$ respectively whereas rest of causes accounting for another $7.1 \%$ of cases.

Progressive decomposition of Porto-hepatic sys- 
tem results in a spectrum of complications serving as determinants of prognosis. Variceal hemorrhage has been recognized since long as one of the life threatening complications and frequent cause of hospitalization. High portal pressure determined in terms of HVPG has direct correlation with variceal formation. However certain relatively noninvasive methods as has been used in this study have reasonable sensitivity with respect to degree of decompensation. ${ }^{11}$

Esophageal varices occur much more frequently as compared to gastric varices, however gastric varices are associated with more serious bleeds and greater mortality. ${ }^{12}$ The risk of bleeding is low in patients with small varices (5\% per year) whereas large varices have an annual risk of bleeding of $15 \% .{ }^{13}$ The life time risk of one bleeding episode from varices is $33 \%$ with $70 \%$ having rebleed. ${ }^{14}$

Frequency of gastric varices in my study turned out to be $10.9 \%$ among total of 421 patients with decompensate cirrhosis, which is comparable to international studies showing a frequency of $5-33 \%$ in cases with cirrhosis. ${ }^{2,3,4}$

Gender distribution among patients with gastric varices was that, out of total of 46 patients, 32 were males and 14 were females. No obvious explanation to this male predominance could be sorted out but the same has been observed elsewhere also.

Patients who develop one or more signs of decompensated cirrhosis ultimately also develop co-existent esophageal varices and portal gastropathy as well. Esophageal varices were found in $76 \%$. Portal gastropathy was seen in $76.4 \%$ of patients. $52.7 \%$ of patients had one or more episodes of bleeding in past.

Gastric varices are responsible for $10-15 \%{ }^{4}$ of all variceal bleeds and rebleeding rate of $34 \%$ to $89 \% .{ }^{15}$ Gasricvariceal hemorrhage has been associated with mortality rate of as high as $45 \% .{ }^{16}$ When compared esophageal varices are associated with overall mortality of $30 \% .{ }^{59}$ In this study $52.7 \%$ of patients with esophageal andco-existent gastric varices bled and percentage of bleeds attributable only to gastric variceal hemorrhage was $5.4 \%$.

Endoscopic evaluation reveals that gastric varices tend to be larger, more tortuous combined with their anatomic location makes their management challenging. Sarin and Ryan described various types of gastric varices. GOV1 is the commonest variant accounting for $74 \%$ followed by GOV2, IGV1 and IGV2 that comprise up to $16 \%$, $8 \%$ and $2 \%$ respectively. ${ }^{2}$ In this study the most frequent variant was GOV1 making up $54.3 \% \%$ followed by IGV1 of $23.9 \%$.

Understanding portal hemodynamic patterns is of utmost importance in order to design different therapeutic measures for management of gastric varices. Hemodynamic in gastric varices are quite different from those of esophageal varices. In past conventional method of portal vein catheterization was used to view portal system of veins and feeding channels of gastric varices. With the advent of new radiological techniques Multi-detector Computer Tomography Portal Venography (MCTPV) has shown promise with good outcomes. ${ }^{17}$

Afferent venous drainage of gastric varices mainly comes from Left Gastric vein, Short Gastric vein or Posterior Gastric veins and drain into inferior vena cava through Gastro-renal shunt or inferior phrenic vein. Similarly drainage into superior vena cava is via azygous vein. Some of these shunts are not present under normal conditions and arise only when portal pressure rises. ${ }^{7,17}$

Knowledge of this portal system anatomy has now revealed why variceal ligation proved unsuccessful in case of gastric varices due to large area of distribution and multiple communications. Similarly increased incidence of rebleeds and ulcer formation has been noted with above measure. ${ }^{17}$

Taking into account this diversity of gastric varices and large vascular bed, use of tissue adhesives and Cyanoacrylate has been very successful with fewer complications, good homeostasis 
and decreased frequency of rebleeds. Similarly Balloon-occluded retrograde obliteration has been tried in various clinical trials. ${ }^{18-22}$

Modified Child Pugh Classification system is a good prognostic indicator that directly or indirectly commensurate with degree of decompensation. ${ }^{23}$ Majority of patients in this study belonged to Child Class B followed by Child Class A and $C$ respectively. The smaller percentage of Child Class $C$ patients may be attributed to overall decreased 1year survival rate.

\section{CONCLUSION}

Gastric varices are present in significant number of patients with decompensate cirrhosis. Since gastric varices are associated with increased mortality and poor outcomes, these should be carefully looked during upper Gl endoscopy. Successful management of gastric variceal hemorrhage necessitates availability of expertise and newer diagnostic modalities.

This study did not reveal any particular risk factor associated with increased frequency of gastric varices however male predominance has been noted.

Copyright@ 17 Aug, 2015.

\section{REFERENCES}

1. Bacon BR. Cirrhosis and its Complications. In: Fauci AS, Braunwald E, Kasper DL, Hauser SL, Longo DL, Jameson $\mathrm{JL}$ et al, (edi). Harrison's Principles of Internal Medicine. 17thed. New York: McGraw-Hill 2012; 1971-80.

2. Sarin SK, Negi S. Management of gastric variceal hemorrhage. Indian J Gastroenterol 2006; 25: 25-6.

3. Ryan BM, Stockbrugger RW, Ryan JM. A pathophysiologic, gastroenterologic, and radiologic approach to the management of gastric varices. Gastroenterology 2004; 127: 1014-5.

4. Garcia-Tsao G, Sanyal AJ, Grace ND. Prevention and Management of Gastroesophageal Varices and Variceal Hemorrhage in Cirrhosis. Am J Gastroenterol 2007; 102: 2086-102.

5. Ismail FW, Mumtaz K, Chawla T, Jafri W. Gastric variceal bleed in a patient without cirrhosis: an unusual cause of hematemesis. Singapore Med J 2007; 48: 171-3.
6. Mumtaz K, Majid S, Shah HA, Hameed K, Ahmed A, Hamid $S$ et al. Prevalence of gastric varices and results of sclerotherapy with N-butyl 2 cyanoacrylate for controlling acute gastric variceal bleeding. World J Gastroenterol 2007; 13: 1247-51.

7. Carlos-Garcia-Pagan J, Barrufet M, Cardenas A, Escorsell A. Management of Gastric Varices. ClinGasteroenterolHepatol 2014; 12: 919-28.

8. Kameda N, Higuchi K, Shiba M, Kadouchi K, Machida $\mathrm{H}$, Okazaki $\mathrm{H}$ et al. Management of gastric fundal varices without gastro-renal shunt in 15 patients. World J Gatroenterol 2008; 14: 448-53.

9. Garcia-Tsao G, Sanyal AJ, Grace ND. Prevention and management of gastroesophageal varices and variceal hemorrhage in cirrhosis. Hepatology 2007; 46: 922.

10. Almani SA, Memon AS, Memon Al, Shah I, Rahpoto MQ, Solangi R. Cirrhosis of liver: Etiological factors, complications and prognosis. J LiaquatUni Med Sci 2008; 7: 61-6.

11. Tarzamni MK, Somi MH, Farhang S, Jalilvand M. Portal hemodynamics as predictors of high risk esophageal varices in cirrhotic patients World $\mathrm{J}$ Gastroenterol 2008; 28; 14: 1898-1902.

12. Datta $D$, Vlavianos $P$, Alisa $A$, Westaby $D$. Use of fibrin glue (beriplast) in the management of bleeding gastric varices. Endoscopy 2003; 35: 675-8.

13. Mukherjee S, Sorrell MF. Beta-Blockers to Prevent Esophageal Varices - An Unfulfilled Promise. N Engl J Med 2005; 353: 2288-90.

14. Frenette CT, Kuldau JG, Hillebrand DJ, Lane J, Pockros PJ. Comparison of esophageal capsule endoscopy and esophagogastroduodenoscopy for diagnosis of esophageal varices World J Gastroenterol 2008; 14: 4480-85. 60.

15. Wang YM, Cheng LF, Li N, Wu K, Zhai JS, Wang YW. Study of glue extrusion after endoscopic $\mathrm{N}$-butyl-2-cyanoacrylate injection on gastric variceal bleeding. World J Gastroenterol 2009; 15: 4945-51.

16. Kochar R, DuPont AW. Primary and secondary prophylaxis of gastric variceal bleeding F1000 Medicine Reports 2010; 2: 26.

17. Zhao LQ, He W, Ji M, Liu P, Li P. 64-row multidetector computed tomography portal venography of gastric variceal collateral circulation World $\mathrm{J}$ Gastroenterol 2010; 16: 1003-7.

18. Irani S, Kowdley K, Kozarek R. Gastric varices: an up- 
dated review of management $\mathrm{J}$ ClinGastroenterol. 2011; 45: 133-48.

19. Cheng LF, Wang ZQ, Li CZ, Lin W, Yeo AE, Jin B. Low incidence of complications from endoscopic gastric varicealobturation with butyl cyanoacrylate. ClinGastroenterolHepatol. 2010; 8: 760-6.

20. Cárdenas A. Management of acute variceal bleeding: emphasis on endoscopic therapy Clin Liver Dis. 2010; 14: 251-62.
21. Sarin SK, Mishra SR. Endoscopic therapy for gastric varices Clin Liver Dis. 2010; 14: 263-79.

22. Kumar A, Singh S, Madan K, Garg PK, Acharya SK. Undiluted $\mathrm{N}$-butyl cyanoacrylate is safe and effective for gastric variceal bleeding GastrointestEndosc. 2010; 72: 721-7.

23. Wakatsuki T, Obara K, Irisawa A, Sakamoto H, Kuwana $T$, Takiguchi $F$ et al. Analysis of prognostic factors in patients with gastric varices after endoscopic treatment Dig Endosc. 2009; 21: 232-8.

\section{3 \\ "Loyalty is so rare now a days. \\ If someone remains loyal to you, appreciate them, don't take them for granted."}

Unknown

AUTHORSHIP AND CONTRIBUTION DECLARATION

\begin{tabular}{|c|c|c|c|}
\hline Sr. \# & Author-s Full Name & Contribution to the paper & Author $=\mathbf{s}$ Signature \\
\hline 1 & Dr. Sarwat Iqbal & $\begin{array}{l}\text { Pricipal author, Data } \\
\text { analysis }\end{array}$ & \\
\hline 2 & Dr. M. Haroon Yousaf & Proof reading, Procedures & \\
\hline 3 & Dr. M. Iftikhar Yousaf & Data collection & \\
\hline 4 & Dr. Wasim-Uddin & Procedures & 700 \\
\hline
\end{tabular}

